Научная статья

УДК 343

https://doi.org/10.36511/2078-5356-2021-4-178-183

\section{Особенности криминалистической характеристики}

преднамеренного банкротства

\section{Красненкова Алена Вячеславовна}

Нижегородская академия МВД России, Нижний Новгород, Россия, alenakrasnenkova@yandex.ru

Аннотация. В статье дана криминалистическая характеристика, содержащая признаки, особенности субъекта, предмета преступления, предусмотренного статьей 196 Уголовного кодекса Российской Федерации (далее - УК РФ), а также описаны способы его совершения и следы, способствующие формированию доказательственной базы.

Ключевые слова: криминальные банкротства, преднамеренные банкротства, специальные знания, специалист-ревизор, эксперт

Для цитирования: Красненкова А. В. Особенности криминалистической характеристики преднамеренного банкротства // Юридическая наука и практика: Вестник Нижегородской академии
МВД России. 2021. № 4 (56). С. 178-183. https://doi.org/10.36511/2078-5356-2021-4-178-183.

Originalarticle

Features of forensic characteristics of intentional bankruptcy

\section{Alena V. Krasnenkova}

Nizhny Novgorod Academy of the Ministry of Internal Affairs of Russia, Nizhny Novgorod, Russian Federation, alenakrasnenkova@yandex.ru

Abstract. The article provides a criminalistic characteristic containing the signs, features of the subject, the subject of the crime provided for in Article 196 of the Criminal Code of the Russian Federation, as well as describes the methods of its commission and traces that contribute to the formation of the vidence base.

Keywords: investigation of documents, criminal bankruptcies, deliberate bankruptcies, special knowledge, specialist auditor, expert

For citation: Krasnenkova A. V. Features of forensic characteristics of intentional bankruptcy. Legal Science and Practice: Journal of Nizhny Novgorod Academy of the Ministry of Internal Affairs of Rus-
sia,2021, no. 4 (56), pp. 178-183. (In Russ.). https://doi.org/10.36511/2078-5356-2021-4-178-183.

В условиях нестабильной экономической Сведения, представленные Центральным банситуации в российской экономике проблема ком Российской Федерации, свидетельствуют о аанкротства становится особо акууальна. Воз- том, что в 2020 гду по сравнению с 2019 годом дусткио вновна йе бизнеса портапкивает его женных процедуре банкротства, сократипось к принатио ренй

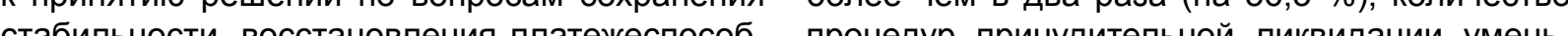
сости либо вы применения процедуры банио 2 В апреле 2020 года бып введен мораторий [а банкотста на срок действия моратория. В на порачу кредитоми заялений о банкротстве. стоящее время о орой внимание необходим Данный факт свиетел количества банкротств по итогам 2020 года. знаков преднамеренных банкротств в связи с

๑) Красненкова А. В., 2021 популяризацией применения упрощенной процедуры банкротств, а также важности проведения комплотого а также важности проведеарминистративно-правов ренных банкротствах в целях опреденения нелостатюе нормативного регулирования в ванной обласи $n$ эффективного истоль во специал

В Федеральном законе от 26 октября 2002 года № 127-Ф3 «О несостоятельности бря 2002 гола N. 127-Ф3 О Оесо 127), в частно(банкротстве)" (далее - Ф3 № 127), в частно"банкротство», дор котор ри понимеется наспособност должния в полном объеме уновлесобность дол, под воторьи понйеме удовлетворить требови ия китори пе денежным бо уплате обязатепьных ппатежей, которая

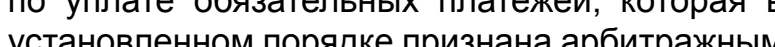
установ. Кпючевую роль играет факт признания судом. Ключев ро̆с итрает факт признания судом в порядке предусмотренном законом судом в пом Российской Федерации [3].

Для субъектов банкротства неспособность определяется с учетом различных оснований, предусмотренных $\$ 3$ № 127 . Так, юридические предусмотренных в случае неудовпетворения в попном объеме требований кредиторов в течение трех месяме требований кредиторов в течение трех месянев с даты, определенной для исполнения «девежных обязательссв, обязательств о выплате работающих или работавших по трудовому договору, и (или) исполнить обязанность по уппате говору, и (или) исполнить обязанность по уплате ные выплаты), признаются неспособными удовлетворить в полном объеме требования кредиторов [3]. В данной ситуации кредиторы имеют право на обращение в арбитражный суд с заявлением о признании должника банкротом и на проведение в установленном законом порядке процедуры банкротства.

В соответствии с постановлением Пленума Высшего Арбитражного Суда Российской Федерации от 30 июня 2011 года № 51 «О рассмотрении дел о банкротстве индивидуальных предпринимателей» индивидуальный предприниматель при наличии неудовлетворенного требования кредиторов по обязательным платежам в течение трех месяцев на общую сумму не менее 10 тыс. рублей после даты их исполнения признается банкротом независимо от превышения суммы его обязательств стоимости принадлежащего ему имущества [4].

Относительно кредитных организаций следует отметить, что сроки исполнения обязательных требований кредиторов заметно сокращень и составляют 14 дней, в отличие от иных орга-

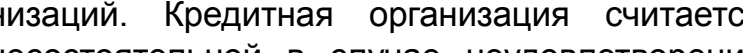
в

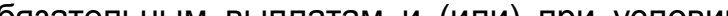
ито стоимость имущест (аки) пр) условии й чо (1)

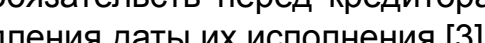

В спучае умьшленй действий (бездейстия) руковорителя учредителей оридического лица или индивидуального предпринитатего, направленных на доведение организации о банкротного состояния, могут усматриваться ризнаки преднамеренного банкротства.

В российском законодательсте о преднамеренном банкротстве следует толковать административно-правовом и уголовно-правоом смыслах. Так, Кодексом Российской Федерации об административных правонаруше-
ниях (далее - КоАП РФ), а именно частью 2 ниях (далее - КоАП РФ), а именно частью 2 признается действие (бездействие) субъектов административного правонарушения, заведомо влекущее неспособность их в полном объеме удовлетворить требования кредиторов по ббязательным выплатам, если оно не содержи уголовно наказуемого деяния [5].

В соответствии со статьей 196 УК РФ преступлением является деяние, заведомо влекущее неспособность юридического лица, индивидуального предпринимателя, гражданина в полном объеме удовлетворить требования кредиторов по обязательным выплатам если совершенное деяние причинило крупный ущерб [6].

Основным объектом преднамеренного банкротства выступают общественные отношения, посягающие на экономическую деятельность, в частности, на нормальное функционирование

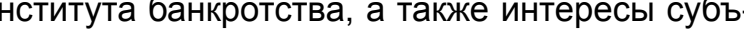
итов этой деятельности. Нельзя не отметить муц й (кредиторов и иных лиц, не получающих блзательных платежей от должника), являющиеся дополнительным объектом противоправдеяния.

сторона преднамеренного баноства заключается в умышленных активных рли пассивных действиях должника, влекущих риесіособности в Полно обьеме удовлетвор.

Наглядным примером неспособности организации отвечать по своим обязательствам 
является увеличение объема обязательств влекущие неспособность ООО «X» в полном должника перед кредиторами, что является объеме удовлетворить требования кредитоследствем необоснованных расходов на ре- ра ООО «С». умышленно осуществлял вывод кламу, покуле дорости ходй Отметим, что вынесенное решение арби- надле. Для реализации своего умыспа Э. С. Г*夫夫

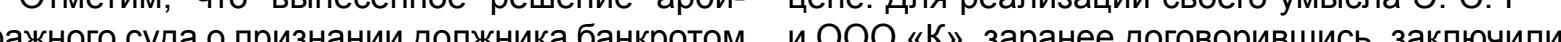
и открытии конкурсного пролзнока банкротом и иОО «к, заранее дововорившись, заключили гивает уголовно-правовые отношения, а лиш портео 作

Выявление, расследование и раскрытие преступлений, связанных с преднамеренными банкротствами, должны сопровождаться проведением оперативно-разыскного мероприятия исследованием документов (в ходе проведения доследственной проверки с целью выявления признаков возможного совершения преднамеренного банкротства) [8], и в ходе расследования соответствующей финансово-аналитической экспертизой, которая является достаточно продолжительной и трудоемкой. Нередко при
обнаружении признаков криминальных банкротств возникает необходимость в проведении комплекса оперативно-разыскных мероприятий.

В целях установления объективной стороны, выраженной в действиях субъектов преступления, следователю или оперуполномоченному противодействия коррупции (далее - ЭБиПК) следует обратить внимание на следующие признаки преднамеренных банкротств:

- участники преступного посягательства активно скрывают имущество (имущественные права / обязанности), сделки с ним, сведения о нем;

- совершают убыточные сделки с имуществом (дарение, обмен на невыгодных условиях, реализуют товары по заниженным ценам, приобретают без особой надобности товары по высокой цене);

- Совершают притворные / мнимые сделки рации (далее - ГК РФ)) [9]

- переводят денежные средства на счета других организаций, выдают безвозмездные или с минимальными процентами займы гражданам, работникам;

средства

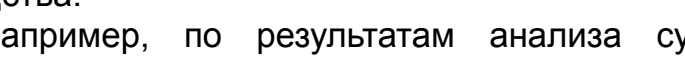
дебно-следственной практики установлено, что Э. С. $\Gamma^{* * *}-$ руководитель юридического лица ООО «Х», совершил действия, заведомо во собственности (договор купли-продажи, акт

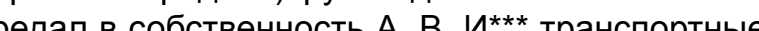
средства [10] лее - ИП) А. П. Т***, занимаясь деятельностью по предоставлению услуг по перевозкам автомобильным грузовым транспортом осу способность исполнить обязанности по оплате налоговых обязательств, что установлено по результатам выездной налоговой проверки, проводимой ИФНС № 5 по Саратовской области, а также удовлетворить требования кредиторов, причинившие крупный ущерб. Инициирование процедуры банкротства в данном случае является способом уклонения от уплаты налоговых ется способом
обязательств.

Для увеличения неспособности в полном объеме удовлетворить требования кредиторов, А. П. Т* совершала мнимые сделки, а именно: оформляла подложные документы, подтверждающие наличие долга по займу денежных средств своим родственникам. Также с целью создания условий невозможности погашения задолженности по обязательным платежам путем заключения договора уступки права требона автомобильном транспорте согласно договору. А. П. Т***, продолжая реализовывать свой преступный умысел, направленный на неправомерный вывод активов, в целях увеличения неплатежеспособности перечисляла с расчетного счета ИП А. П. Т**夫, открытого в ПАО «Сбербанк», себе на дебетовый счет, после чего переводила денежные средства на расчетный счет своей родной тети, составляя при этом подложный доствила вывод денежных средств с целью уклонения от уплаты налоговой задолженности, в счет погашения сомнительной, не подтвержденной
задолженности аффрилированным лицам [11].
Индивидуальный предприниматель (даществляла действия, заведомо влекущие невания реализовала свою цель, то есть уступила право требования ИП «Т» (своей родной сестре) говор займа. Таким образом, А. П. Т*** осуще-
Зачастую фирмы-кредиторы в действительности являются фиктивными.

В целях установления объективной стороны, выраженной в бездействии субъектов преступления, следователю или оперуполномоченному подразделений ЭБиПК следует обратить внимание на спедующие признаки:

- сокрытие имущества (имущественных прав и обязанностй), а также сведений о нем; - целенаправленное прекращение текущих платежей;

- досрочное погашение долгов, залогом которых является недвижимость, за счет заемных средств более крупного должника.

Анализируя судебно-следственную практику, следует акцентировать внимание на способе совершения преступления, основным из которых при преднамеренном банкротстве является реализация в пользу третьих лиц ликвидного различна, например, передача имущества оргаразлична, например, передача имущества оргапростой и распространенный способ (наиболее ки) может реализоваться путем:

- продажи без фактической оплаты: зачастую следы преступления отражены в таких документах хозяйствующего субъекта (в зависимости от специфики деятельности), как договор купли-продажи (основных средств, нематери алли-подажи (основов, других внеобортоных активов), акт сверки взаимных расчетов, акт о приемепередаче ликвидных активов, накладная, счетфактура, платежное поручение;

- по заниженной цене относительно рыночной: следы, как правило, отражены в таких документах, как договор купли-продажи недвижимых объектов, договор лизинга, акт приемапередачи основных средств, счет-фактура.

В практической деятельности реже встречается способ маскировки следов преступной деятельности, заключающийся в передаче имущества другой организации с целью погашения фиктивной кредиторской задолженности, для использования его в качестве вклада в уставный капитал, для сдачи в аренду.

Состав преступления, предусмотренный статьей 196 УК РФ, по законодательной конструкции является материальным, то есть в результате причинения крупного ущерба преступление считается оконченным. Размер крупного ущерба и составляет 2 млн 250 тыс. рублей. [6].

Поскольку функционирование института банкротства регулируется достаточно широким кругом нормативных правовых актов, то диспозиция нормы статье 196 УК РФ представ-

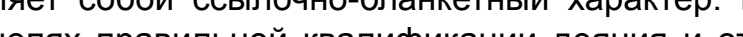
раничения от смежных составов следует обратиться к гражданскомy, налоговому занонодарати регулирующим рассматриваемую сореру.

Субъекты преступного посягательства специальные:

а) ИП - физическое лицо, которое зарегистрировано в федеральной налоговой службе 作, предусмотренном налоговым занонодательством, с целью ведения предпринимательской деятельности без образования оридического лица. В случае осуществления прдивиуальной предпринимательской деяельности, попадающей под условия, предусмотренные налоговым и гражданским законодаельством (п. 1 ст. 23, п. 1 ст. 25 ГК РФ; ст. 11 они не имеют возможности удовлетворить требования кредиторов;

б) руководитель или учредитель (участник) оридического лица, то есть организации, имеющей в хозяйственном ведении ипи оперативном управлении обособленное имущество, отвечающей по своим обязательствам этим имущетвом, наделенной гражданскими правами;

в) гражданин - физическое, вменяемое ное удовлетворить требования кредиторов по обязательным выплатам.

Субъективная сторона противоправного деяния выражена в форме вины с прямым умыслом. Согласно материалам судебной практики (судебный приговор № 1-81/2020 от 13 мая 2020 года в отношении генерального директора ООО «A» C. Е. Ш очисткой воды, организацией перевозок грузов, удалением и обработкой сточных вод, удалением и обработкой твердых отходов и оказанием прочих персональных услуг). Так, установлено, что С. Е. Ш ${ }^{* * *}$ допустил значительное увеличение неплатежеспособности ООО «А» путем заилючения сделок по отчуждению имущества на условиях заведомо невыгодных для ООО «А», влекущих неспособность должника в полном объеме удовлетворить требования кредиторов. Реализуя преступный умысел С. Е. Ш ясь единоличным исполнительным органом, выолняющим административно-хозяиственные организационно-распорядительные функции, аключил с ООО «Г» договоры купли-продажи: транспортного средства (машина ассенизационная (вакуумная) КО-529-11) стоимостью 
142000 рублей, в то время как рыночная стоимость составляла 534331 рублей, то есть стоимость занижена на 392 из1 рублей; транс219000) стоимостью 10000 рублей, в то время как ее рыночная стоимость составляла 219159 рублей, то есть стоимость занижена на 209159 рублей; транспортного средства (машина для очитью 25000 рубпей, в то время как ры) стоистоимость составпяпа 858252 рублей, ТО есть стоимость составляла 858252 рублей,

Таким образом, генеральный директор ООО «А» посредством заключения договоров купли-продажи и проведения по ним расчета осуществил вывод пиквидных активов рыночной стоимостью 8 млн 798 тыс. рублей, своими действиями лишил юридическое лицо ООО «А воиможности удовлетворить требования «А диторов в полном объеме, причинив крупный ущерб [12].

Преступная цель не определена уголовным законом, однако по сути таковой является уклонение от соответствующих платежей: налоговых, страховых обязательств, заемных средств, кредитованных средств и иных обязательст перед кредиторами.

Преднамеренные банкротства негативно влияют на экономику, благосостояние граждан, функционирование организаций в целом в этом и заключается их повышенная общественная опасность. Количество финансово-хозяйствующих субъектов, находящихся в предбанкротном состоянии, только возрастает Что касается практической деятельности опе ративных и следственных подразделений, то собранные материалы, содержащие признаки преднамеренного банкротства, малоперспективны в уголовном судопроизводстве. Данный факт связан, во-первых, с отсутствием универсальных методических рекомендаций по установлению ущерба, причиненного в результате совершения противоправной деятельности во-вторых, недостаточным взаимодействием между правоохранительными органами арбитражными управляющими по вопросам выявления признаков, свидетельствующих совершении преднамеренного банкротства. Вывод следует из анализа судебно-следственной практики, опроса практических сотрудников органов внутренних дел и анализа статистических данных.

Таким образом, в целях противодействия преднамеренным банкротствам необходим совершенствовать методическую и нормативно правовую базу, регулирующую функционирование института банкротства по следующим направлениям: при взаимодействии органов внутренних дел и арбитражных управляющих установить максимально короткие сроки предоставпения сведений о признаках преднамеренного банкротства и иной необходимой для оперативно-разыскной деятельности информации; разработать универсальную методику проведения документального исспедования по делам О банкротстве в целях правипьного установления ущерба, причиненного в результате осуществления противоправной деятельности, используемую как специалистами-ревизорами отдепа (отдепения) документапьных исспедований, так и экспертами при проведении финансово-ана-

\section{Список источников}

1. Добровлянина О. В., Кондратьева К. С., Патырбаева К. В. Виды незаконных банкротств в Российской Федерации: некоторые проблемы правового регулирования // Право. Журнал Высшей школы экоммики. 2017. № 3.

2. Прекращение деятельности финансовых организаций 2020/2019. URL. hitp://www.cbr.ru/Collection/ Collectin

3. О несостоятельности (банкротстве): федеступ из СПС КонсультнтПпюсу (дата обращения: 04.05.2021). альных предпринимателей: постановление Пленума № 51. Доступ из СПС «КонсультантПлюс» (дата обращения: 05.05.2021)

5. Кодекс Российской Федерации об административных правонарушениях: федеральный закон от 30 декабря 2001 г. № 195-Ф3. Доступ из СПС «Кон сультантПлюс» (дата обращения: 10.04.2021).

6. Уголовный кодекс Российской Федерации: федеральный закон Российской Федерации от 13 июня 1996 г. № 63-Ф3. Доступ из СПС «КонсультантПлюс»

7. Сверчков В. В., Воронов С. С. Преднамеренное банкротство юридического лица или индивидуальдения и особенности квалиффикации // Юридическая наука и практика: Вестник Нижегородской академии МВД России. 2013. № 21

8. Об оперативно-розыскной деятельности: феступ из СПС «КонсультантПлюс» (дата обращения: 19.04.2021). питической экспертизы.

4. О рассмотрении дел о банкротстве индивиду-
9. Гражданский кодекс Российской Федерации часть первая): федеральный закон от 30 ноября (дата обращения: 03.05.2021).

10. Приговор Ахтубинского районного суда (Астраханская область) № 1-74/2020 от 14 апреля 2020 года по делу № 1-74/2020. Доступ из СПС «КонсультантПлюс» (дата обращения: 03.05.2021).

11. Приговор Ртищевского районного суда (Саратовская область) № 1-22/2020 от 19 февраля 2020 Плюс» (дата обращения: 10.05.2021).

12. Приговор Киреевского районного суда (Тульская область) № 1-81/2020 от 13 мая 2020 г. Доступ из СПС «КонсультантПлюс» (дата обращения

\section{References}

1. Dobrovlyanina O. V., Kondratyeva K. S., Patyrbaeva K. V. Types of illegal bankruptcies in the Russian Federation: some problems of legal regulation. Law. Journal of the Higher School of Economics, 2017, no. 3. (In Russ.)

2. Termination of activities of financial organizations 2020 / 2019. URL: http://www.cbr.ru/Collection/Collection/File/32063/termination_activities_tin
(accessed 08.04.2021). (In Russ.) Russian Federation no. 127-FZ of October 26, 2002. Ac cess from the reference legal system "ConsultantPlus"
(accessed 05.04.2021). (In Russ.)

4. On consideration of bankruptcy cases of individual entrepreneurs: resolution of the Plenum of the Supreme
Arbitration Court of the Russian Federation no. 51

Статья поступипа в редакцию 30.08.2021; одобрена после рецензирования 29.10.2021; принята к публикации 13.12.2021.

The article was submitted 30.08.2021; approved after reviewing 25.10.2021; accepted for publication 13.12.2021.

of June 30, 2011. Access from the reference legal sys-
tem "ConsultantPlus" (accessed 05.05.2021). (In Russ.) 5. Code of the Russian Federation on Administatie Offenses: federal law no 195-FZ of December 30, 2001. Access from the reference legal system "ConsultantPlus" (In Russ.)

6. The Criminal Code of the Russian Federation: federAaw of the Russian Federation no. 63-FZ of 13.06.1996 Access from the reference legal system "ConsultantPlus"

7. Sverchkov V. V., Voronov S. S. Intentional bank7. Academy of the Ministry of Internal Affairs of Russia 2013, no. 21. (In Russ.)

8. On operational-search activity: federal law no. 144 "August 2, 195. Access from the reference legal sys-

9. Civil Code of the Russian Federation (Part One): from the reforence legal system "ConsultantPlus" (accessed 03.05.2021). (In Russ.)

10. The verdict of the Akhtubinskiy District Court (Astakhan Region) of April 14, 2020 in case no. 1-74 / 2020 (access from the reference legal system "ConsultantPlus" 5.2021). (In Russ.)

verdict of the Rtishchevsky District Court (1) case "ConsultantPlus" (accessed 10.05.2021). (In Russ.)

12. The verdict of the Kireevsky District Court (Tula Region) no. 1-81/2020 of May 13, 2020. Access from 1994 г. № 51-Ф3. Доступ из СПС «КонсультантПлюс» по делу № 1-22/2020. Доступ из СПС «Консультант-

3. On insolvency (bankruptcy): federal law of the . 